\title{
Study on the Construction of College Second Classroom Personalized Stratified Education System
}

\author{
Xiao-yan Liu \\ Youth League Committee of Yangtze University, Jinzhou, Hubei, China
}

\begin{abstract}
Based on the second classroom, implement personalized stratified education of college students, do the people's satisfaction of education, to achieve the objective requirements "target long-term education development plan"; is to improve the quality of higher education, the beneficial exploration of the cultivation of innovative talents; it is consistent with the law of education and the essence, an important means to reflect the Education Fair Department of college students; it is to implement the central spirit of the document 16, build "important way to transfer positive energy, achievement prize dream" campus culture. Stratified education system should be constructed to demand the students' growth oriented based on the second classroom; to be set up to comprehensively enhance the personalized stratified system of education with the aim of the comprehensive quality of college students; to construct personalized stratified education system to the belief education of college students for the purpose of.
\end{abstract}

Keywords - the second classroom, personalized stratified education, system, construction

\section{大学生第二课堂个性化分层育人体系构建研究}

\author{
刘小燕 \\ 共青团长江大学委员会, 荆州, 湖北, 中国
}

摘 要 立足第二课堂, 对大学生实行个性化分层教育是立德树人、办人民满意教育, 实现国家教育发展规划纲要目标的客 观要求; 是提高高等教育质量, 培养创新型人才的有益探索; 也是符合教育规律和本质, 体现教育公平的重要手段; 更是高校学 生工作部门落实中央 16 号文件精神、构建“传递正能量、成就出彩梦”校园文化的重要途径。立足第二课堂须构建以大学生个性化 成长需求为导向的分层育人体系; 须构建以大学生综合素质全面提升为目标的个性化分层育人体系; 须构建以大学生信仰教育为 宗旨的个性化分层育人体系。

关键词 第二课堂, 个性化分层育人，体系，构建

\section{1. 大学生第二课堂个性化分层育人体系的含义及现} 状

大学生第二课堂个性化分层育人体系, 即大学学生 工作部门或与学生工作有关的部、处、院系联合, 立足 第二课堂, 以学生个性化成长需求为导向, 充分利用校 内外现有人、财、物等资源为学生个人或相同需求的学 生群体, 量身打造的工作或活动, 以直接作用于学生某 方面的素质拓展或心智成长。所有的这些工作形成一整 套制度、框架、规范、体系和传统, 甚至在产生了较明 显的育人效果、被学生和社会所认同后即为“大学生第二 课堂个性化分层育人体系”。

目前, 我国各高校立足第一课堂开展大学生的个性 化分层教育的历史较悠久, 办法较成熟, 学校重视力度 较大。如: 人才的大类培养、专业分流、各种特色人才 班、卓越计划班; 部分教育部重点高校, 如华中科技大
学的“启明学院”, 浙江大学的“竺可桢学院”等; 还包括: 各种不同类型课程的开发与建设、强调不同学科学生专 业学习的交叉融合、第二学士学位辅修制等都不同程度 的为学生的个性化专业学习需求提供了平台。

就第二课堂而言, 各高校近年来开始逐渐重视, 都 有不同程度的实践探索, 具有短期性、碎片化、随意性 等特点, 还未形成较成熟、较系统的规范、框架、制度、 传统和体系。而近几年大学生的发展特点表现为他们对 第二课堂的成才依存度越来越高。对于花费在第二课堂 的时间和精力较多、收获较大的学校和学生, 这种依存 度甚至还超过了对第一课堂的成才依存度。因此, 立足 第二课堂, 构建大学生个性化分层育人体系已迫在眉睫、 大有可为且势在必行。 


\section{2. 大学生第二课堂个性化分层育人体系构建意义}

2.1 构建大学生第二课堂个性化分层育人体系是实现立 德树人、办人民满意教育, 实现教育发展规划纲要 目标的客观要求

2010 年我国颁布的《国家中长期教育改革和发展规 划纲要 (2010- 2020 年)》提出未来 10 年教育发展的战 略目标是: 基本实现教育现代化, 基本形成学习型社会, 加快从教育大国向教育强国, 从人力资源大国向人力资 源强国迈进, 为中华民族伟大复兴和人类文明进步做出 更大贡献[1]。还提到要因材施教, 把全面发展与个性发 展统一起来, “关心每个学生, 促进每个学生主动地、生 动活泼地发展, 尊重教育规律和学生身心发展规律, 为 每个学生提供适合的教育”, 及“创新人才培养模式。适 应国家和社会发展需要, 尊重教育规律和人才成长规律, 深化教育教学改革, 创新教育教学方法, 探索多种培养 方式, 形成各类人才辈出、拔尖创新人才不断涌现的局 面。”党的十八届三中全会提出深化教育领域综合改革, 坚持立德树人, 提高高校人才培养质量。这些都为此项 工作提供了政策依据。因此, 作为高等学校目前最首要 的任务是满足学生个性化成才需求、抓住校内外教育资 源、千方百计提高人才培养质量。高校历来育人有两大 主阵地: 即第一课堂和第二课堂。而立足第二课堂, 针 对不同类型学生的特点和学生不同时期的需要, 开展分 层分类引导, 搭建不同的成长平台, 既有效填补了第二 课堂育人的空白, 更是对第一课堂育人的良好补充, 以 达到双管齐下全方位提高人才培养质量、立德树人, 实 现教育现代化的目的。

2.2 构建大学生第二课堂个性化分层育人体系是回答 “钱学森之问”，培养创新型人才的有益探索

“为什么我们的学校总是培养不出杰出人才? ”2005 年钱学森之问开始吒问中国的高等教育。钱老曾说: “现 在中国没有完全发展起来，一个重要原因是没有一所大 学能够按照培养科学技术发明创造人才的模式去办学, 没有自己独特的创新的东西, 老是“冒”不出杰出人才。这 是很大的问题。”持续引发社会各界广泛评议的“钱学森 之问”, 凝聚了老一辈东方赤子对中国未来命运的深度关 注和热切期待, 也成为我国创新型人才培养征途上函待 破解的难题。2010 年温家宝总理指出: “一所高校想培养 出一流的人才, 追求一流的大师, 必然是培养具有“独特 的灵魂'的创新能力的人才, 没有个性, 何谈创新”? 中 国的大学并不缺乏大楼、大师, 但仅此是不够的! 正如, 决定人类社会发展的是新思想和新观念, 一所大学最可 贵的不是外在的“硬实力”，而是其内在的“软实力”。而 一所自由开放的大学本质上就是新思想、新观念的孵化 地, 就是允许学生顺着自己的兴趣、个性和特长有所为、
有所获、有所悟、进而有所成！

“君子和而不同，小人同而不和”，因此，构建第二 课堂个性化分层育人体系就是要借助第二课堂这个广阔 平台，打破“千人一面”，符合创新型人才培养的规律。 让学生顺着天资和禀赋, 为着理想和目标, 伴着激情和 狂热, 面对人生, 做出选择, 实践探索, 感受创造, 有 所作为。这样才可能创造出适宜创新型人才“冒”出来的 空气和土壤。

2.3 构建大学生第二课堂个性化分层育人体系是符合教 育规律和本质，体现教育公平的重要手段

传统意义上的教育，用一个近乎完美的“标准”来塑 造所有的人。公平的因材施教就是要承认人与人间的 差异化特征，根据每个人的培养潜质、采取不同的方法, 把每个人培养成他应该和想成为的人, 进而各尽其用, 方显其才。

卓有成效的教育，历来都是尊重个性、以人为本的 教育, 如: 钱学森先生早年所在的美国加州理工学院就 是一个重视个性化教育的典型案例, 我国伟大的教育家 孔子曾提出的“有教无类”“因材施教”的个性化教育原则 和方法。教育不是灌满一桶水而是点燃一把火, 没有教 不好的学生, 只有不称职的老师或不合适的方法。对学 生进行个性化的分层教育, 从承认并尊重学生的个体差 异角度出发, 以个体成才诉求为导向, 充分发挥学生的 主体作用, 为不同类型的学生提供个性化发展的目标、 路径、模式和评价, 既体现了对生命的关怀和对人的价 值的尊重, 也体现了教育的真谛、诠释了教育的本质。 只有按照每位学生的特点和需求, 按照不同阶段学生的 特点和需求, 开展有针对性的、个性化的教育, 健全人 格、成熟心智、进而成为各行各业的有用之才，才是教 育公平的重要体现。每位受教育者理应有享受这种教育 的权利。

2.4 构建大学生第二课堂个性化分层育人体系是高校学 生工作部门加强和改进大学生思想政治教育, 构建 “传递正能量、成就“出彩梦””的青春朝气的校园文化 的重要途径

随着高等教育综合改革的不断深入、大学生思想政 治工作有效性的日益强化以及 90 后大学生的新特点, 高 校的学生工作无论是形式还是内容都发生了巨大的变 化, 正视其变化、转变理念、探索新机制, 是新形势下 做好学生工作的关键。大学校园里的第二课堂活动也将 由原来的规模化、大众化、政治化、同质化, 转变为小 型化、小众化、人文化、个性化、差异化。只有这样才 能充分满足 90 后大学生的需求和特点, 才能适应全球化 信息化时代对大学生提出的新要求, 才能符合大学校园 
应有的学术、宁静、多元、青春等气息。习近平总书记 提出: 生活在我们伟大祖国和伟大时代的中国人民, 共 同享有人生出彩的机会, 共同享有梦想成真的机会, 共 同享有同时代一起成长进步的机会。所以负责大学生第 二课堂工作的学生工作部门理应充分认识这一点, 构建 符合当今大学特点, 受青年大学生喜爱的“传递校园正能 量、成就学生“出彩梦””的生动活泼的校园文化氛围。

\section{3. 大学生第二课堂个性化分层育人体系构建模式初 探}

3.1 构建立足第二课堂, 以大学生个性化成长需求为导 向的分层育人体系, 打造第二课堂的隐型课程“超 市”

2004 年《中共中央国务院关于进一步加强和改进大 学生思想政治教育的意见》(中发 16 号文件) 明确指出, 要 “以大学生全面发展为目标”, “坚持教书与育人相结 合”, “坚持教育与管理相结合”, “要把大学生思想政治 教育摆在学校各项工作的首位, 贯穿于教育教学的全过 程”[2]。这为新形势下高校的学生工作提供了明确的指 导思路。为此, 我们要实现从“学校的提供为中心, 学生 选择”的模式到以“学生的需求为导向, 学校满足”模式的 转变。切实以学生成人成才的个性化需求作为开展学生 工作和第二课堂活动的出发点和落脚点, 构建服务式教 育发展新模式。即加强学生工作的服务理念, 尊重受教 育者的主体地位和自主意识, 倡导“以人为本”的第二课 堂工作新模式。具体模型为:

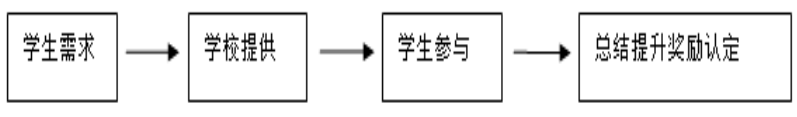

图 1 “以人为本” 第二课堂工作模型

3.1.1 学生需求为导向: 开展“一定要面对面, 一个都不能 少”的双向互动谈心工作

学校的最高使命就是让每一个学生都能够健康成 长, 其前提就是首先要对教育对象有一个准确的了解, 根据其个性特点和利益诉求开展工作。正如清代启蒙思 想家魏源所说: “不知人之短, 不知人之长, 不知人长中 之短, 不知人短中之长, 不可教人”。充分了解学生、走 近学生, 最好方式即是一人一事、交心谈心的“面对面”, 给予他们每一个人应有的关注、适时的教育、正确的指 导和必要的帮助; 贯彻落实中央 16 号文件精神, 加强和 改进大学生思想政治教育, 最有效的途径即是把解决学 生实际问题和解决学生思想问题结合起来。学生思想政 治工作和高等教育“抓两头带中间”既不符合人才成长规 律, 也不能体现教育公平、有教无类和因材施教。要坚
持学生面上教育和个体教育相结合, 认真做好“一定要面 对面, 一个都不能少”的谈心工作。

老师与每一位学生交心谈心, 不仅增强了全校教职 工诲人不倦的使命感, 也让学生打开了心扉、使学校了 解学生个体的特点和差异化需求, 以便因材施教。除此 之外, 使学生在谈心工作中“反客为主”, 形成“老师约谈 学生, 学生约谈老师”的双向互动式融洽的师生谈心机 制, 对尊重学生平等受教育的主体地位、满足学生个性 化成才诉求和融洽师生情感起到了重要作用。

3.1.2 活动“超市”为平台: 构建“万人创百星”工程统领的 校园科技文化活动方阵群满足学生个性化的活动需求。

(1) “万人创百星”活动简介。在“数万”学生中选出 “百名”左右的校园明星, 即“万人创百星”。“万人创百星” 是由高校学生工作部门牵头主办的全校性的大型特色综 合性活动。给更多的同学提供“锻炼特长技能, 展示青春 风采, 彰显个性魅力”的空间和舞台, 培养大学生的差异 化素质, 提高综合素质, 培养一大批“学习好、能力强、 特长亮、威信高”的优秀学生, 同时为了挖掘学生中先进 典型, 示范和启迪大批的学生健康成才。根据学生个性 特长, 评选校园学习明星共 15 大类校园明星。这个评价 体系鼓励学生在专业成绩合格的基础上, 适当发展个性 特长、打造差异化素质, 培养核心竞争力。

(2) “万人创百星”系列平台活动方阵群

表 1 “万人创百星” 平台活动方阵群及相关明星评选对照表

\begin{tabular}{|c|c|c|}
\hline 学生需求 & 学校提供活动 “超市” & 奖励认定 \\
\hline $\begin{array}{l}\text { 唱歌及舞台 } \\
\text { 表演活动 }\end{array}$ & $\begin{array}{l}\text { “想唱就唱”周末卡拉 OK 大赛; } \\
\text { 大学生芝术团、地平线合唱团及校 } \\
\text { 外演出活动 }\end{array}$ & 校园舞台明星 \\
\hline 学习科研 & $\begin{array}{l}\text { 专业基本功大赛 “学习创新中心” } \\
\text { 各项科研立项等活动、学科竞赛、 } \\
\text { 挑战杯等 }\end{array}$ & $\begin{array}{l}\text { 校园学习明星 } \\
\text { 校园科研明星 }\end{array}$ \\
\hline 体育运动 & 国、省、校务种体員赛 & 校园体育明星 \\
\hline $\begin{array}{l}\text { 公益活动、志 } \\
\text { 愿服荌 }\end{array}$ & $\begin{array}{l}\text { 各级各类志愿服务活动、公益创意 } \\
\text { 策划大大赛、社会实践活动 }\end{array}$ & $\begin{array}{l}\text { 校园公益明星、 } \\
\text { 校园道德明星 }\end{array}$ \\
\hline $\begin{array}{l}\text { 主持、演说、 } \\
\text { 语言表演 }\end{array}$ & $\begin{array}{l}\text { “想讲就讲” 大学生中英文讲坛, } \\
\text { 大学生演讲、辨论赛、论坛等活动, } \\
\text { 广播台、艺术团主持人等 }\end{array}$ & 校园口才明星 \\
\hline 书画摄影 & $\begin{array}{l}\text { “想秀就秀”大学生个人妄场展示 } \\
\text { 活动、参加书画摄影类比赛, 举办 } \\
\text { 书画摄影展 }\end{array}$ & 校园美术明星 \\
\hline $\begin{array}{l}\text { 新闻写作、文 } \\
\text { 学创作 }\end{array}$ & $\begin{array}{l}\text { “想写就写”个人校园文化作品集 } \\
\text { 出版、参加写作类比赛、校内外撰 } \\
\text { 稿人 }\end{array}$ & $\begin{array}{l}\text { 校园创作明星 } \\
\text { 校园传媒明星 }\end{array}$ \\
\hline 组织管理 & $\begin{array}{l}\text { 担任班、院、校、社团等学生干部; } \\
\text { 参加学生干部三级培训、女子学院 }\end{array}$ & 校园学干明星 \\
\hline 创意策划 & $\begin{array}{l}\text { 参加相关比赛或担任相关组织或 } \\
\text { 活动的策划人 }\end{array}$ & 校园策划旧星 \\
\hline 创业实践 & 参加创业实践 & 校园创业明星 \\
\hline 自立自强 & $\begin{array}{l}\text { 家庭较贫困或生活遇到重大挫折, } \\
\text { 或身体缺陷仍有学习成绩优秀或 } \\
\text { 某些方面特长能力突出等自立自 } \\
\text { 强的表现 }\end{array}$ & 校园自强明星 \\
\hline 其他 & $\begin{array}{l}\text { 参加校内、外与申报明星相关的各 } \\
\text { 种活动表现突出 }\end{array}$ & $\begin{array}{l}\text { 自创类别明星。 } \\
\text { 如: 英语风,采明 } \\
\text { 星、军旅明星 }\end{array}$ \\
\hline
\end{tabular}

3.3.3 “校园明星”来认定: 按照各类明星积分评定标准申 报、评选、表彰和奖励学生。

前期各类校园明星评价指标体系的科学设计和不同 类型品牌活动的开展, 中期校园明星的申报、测评、评 
选表彰以及后期校园明星社会实践、校园明星座谈会、 明星事迹报告会三部分构成了完整的“万人创百星”工 程。学校学生工作部门于每年的 10 月至第二年的 4 月开 展“万人创百星”的评选表彰活动。通过自主申报、初选、 复选和投票评选等环节, 共评选出“校园学习明星”、“校 园科研明星”、“校园学干明星”等 15 大类“校园明星”100 人左右。学校还要针对评选出来的“校园明星”开展诸如: 素质拓展、赴香港高校游学交流、赴大型企业实践交流、 赴革命圣地社会实践、校园明星先进事迹巡回报告会等 一系列活动。该项活动的举办, 将会丰富校园文化生活, 浓厚校园育人氛围, 推动校园文化建设, 为青年成长指 明方向, 为青年个性发展提供舞台, 同时在学生、家长 和社会中产生积极影响。

3.2 构建立足第二课堂, 以大学生综合素质全面提升为 目标的个性化分层育人体系, 打造学生综合素质培 训的“学校”。

3.2.1 指导支持特长精湛学生举办高质量的个人专场才艺 展示活动。

对于能力特长尤为显著的学生, 前期他们在现有的 “万人创百星”活动方阵群的平台上进行初级的实践训 练, 能力得到提升后, 应本着“关注大众, 培育精英”的 原则, 根据他们的愿望, 指导支持他们举办“想秀就秀.个 人专场才艺展示活动”或“想写就写. 校园文化作品集出 版”。让他在独立的、个性化、专业化的舞台上继续发现、 发挥、发展自己。这种以“自我为唯一主体的个性化才艺 展示活动” 的特点是: 个人既是导演又是主演, 既是运动 员又是裁判员, 既是评委又是观众, 既是专家又是学生。 在这个过程中学生工作部门应给予他们更多的精神和物 质上的、全过程的帮助和指导。活动系统的策划实施, 这种经历会让他受益终生, 专业素质更会得到升华。具 体模型为:

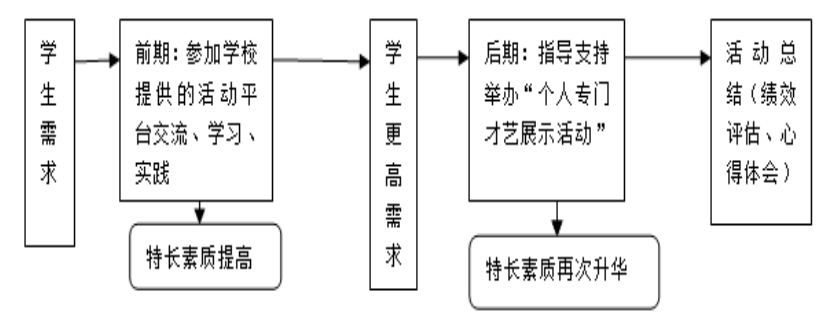

图 2 自我为唯一主体的个性化才艺展示活动模型

3.2.2 通过个人专场展示活动的指导开展, 全面提升学生 的专业素质和组织策划能力。

为确保活动的可持续发展, 学校要建立《大学生个性 化活动指导管理办法》等制度, 设立“大学生个性化教育 培养专项基金”，从个性化活动的范围界定、质量要求、
立项支持、举办流程和注意事项等方面全过程指导学生 开展个性化活动。使具有某方面突出特长的同学“想秀就 秀”, 举办诸如个人演唱会、个人舞蹈专场晚会、个人书 画摄影作品展等个人专场展示活动; 使擅长文学创作的 同学“想写就写” 编辑出版校园文化作品集, 校内结集出 版或公开出版。

把学生的申请按照水平高低分别给予校、院两级集 中立项举办, 活动经费采取学校、学院和学生个人各出 三分之一的原则进行。总之, 一次成功的学生个性化专 场展示活动需要大批老师的无私奉献和系统指点, 需要 学生从前期策划、事中组织到事后总结全过程的实践训 练, 更需要大量不同风格、较高水平作品的集中呈现, 方能实现校园里的“明星梦”、“作家梦”和“出彩梦”。对学 生而言, 使学生在此过程中不仅全面拓展和检阅了自己 的专业特长, 也使自身的综合素质甚至思想境界得到了 较大的提升。对学校而言, 丰富了学生的业余文化生活, 繁荣了校园文化、提高了校园文化品味, 拓展了实践育 人的平台。“一沙一世界, 一叶一菩提”, 对于学生而言, 亲身参与、全过程独立举办的一次个性化活动, 是系统 培育学生综合素质的“学校”!

3.3 构建立足第二课堂, 以大学生信仰教育为宗旨的个 性化分层育人体系, 打造培育未来社会精英的团校。

高校各级各类学生干部约占全体学生的三分之一。 这个特殊的群体不仅是学校老师行使教育管理职能的得 力助手, 也是学生干部自身组织管理协调能力锻炼实践 的重要舞台, 更是学生群体实现自我教育自我管理自我 服务的中坚力量。因此, 学生干部教育培养工作做好了, 学生干部的素质提高了, 会大大优化学校的校风和学风, 形成“正能量”的传递和示范效应。2006 年 6 月 5 日, 胡 锦涛总书记做出重要批示: “重视并加强对学生干部的培 训和实践锻炼是一件有深远意义的事情, 要注意总结各 地行之有效的经验, 引导一大批优秀学生干部健康成 长。”2006 年 10 月团中央下发了《高校学生干部培养规 划(2006-2010)》, 并明确提出了要以此为契机培养一大 批青年马克思主义者。因此, 加强和改进大学生思想政 治教育, 一个重要的环节就是加强学生干部的分层分类 培训, 培养学生干部坚定信仰、高尚道德和较高素质, 并通过学生干部的榜样示范效应带动全校学生良好素质 的形成。而信仰教育处于理想信念教育的最高层次, 是 世界观、人生观和价值观教育体系中的终极部分, 为此, 加强以大学生信仰教育和能力提升为宗旨的学生干部分 级培训就成为高校学生工作部门的重点工作。这也是学 习贯彻习近平总书记系列重要讲话精神, 培养中国特色 社会主义事业合格建设者和可靠接班人的一项重要战略 举措和政治任务。

学生干部培训工作的重要性决定了须以严谨规范的 
教学实践活动的要求组织开展, 使之规范化、长效化、 制度化和个性化。须以不同年级、不同岗位的学生干部 的个性化培训需求为导向, 将学生干部培训班分为三个 不同的层次, 即: 常识班 (初级)、技能班 (中级) 和信 仰班 (高级)。针对不同层次培训对象的岗位特点和发展 需求, 采用不同的培训方式, 制定不同的培训计划和目 标, 设定不同的培训周期, 分层分类加以培训和引导。

3.3.1 着眼学生发展, 以中低年级学生干部的能力提升需 求为导向, 设置常识班和技能班。

常识班 (初级) 是学生干部培训的起点和基础, 是 针对新生班级干部、校级或院级学生组织中新吸纳的大 一大二低年级干事级学生干部, 开展的学生干部基本常 识、理论、素养和方法的普及培训。培训形式以“大班授 课为主、小班活动为辅”、“理论教学为主、实践训练为 辅”; 技能班 (中级) 是学生干部培训的延伸和拓展, 是 针对参加过常识班的优秀学员、大二大三年级学生干部

（班干部或校、院两级学生组织中的部长级干部）开展 的学生干部工作执行力、具体工作技能的深度培训。因 此, 根据不同岗位工作的特点, 中级班又分为: 新闻写 作培训班、办公自动化培训班、社团干部培训班、志愿 服务组织学生干部培训班、艺术组织学生干部培训班等。 培训形式以“小班授课为主、大班授课为辅”、以“实践训 练为主、理论传授为辅”。

3.3.2 着眼国家需要, 以中高年级学生干部的信仰教育需 求为重点, 设置信仰班。

中央 16 号文件指出, 加强和改进大学生思想政治教 育, 要以理想信念教育为核心, 深入进行正确的世界观、 人生观、价值观的教育。信仰是一切事业的基石、源泉 和逻辑起点, 信仰改变命运、信仰塑造品格, 信仰产生 道德观, 道德观产生道德行为。信仰不因环境挫折等而 改变, 信任的极端化就是信仰。信仰不是与生俱来的, 他可以在优良的教育中培养, 也可以在爱的熏陶和适合 的环境中萌发。青年马克思主义培训班承担着孕育并坚 定优秀学生干部人生信仰的重任。

大学生信仰教育是指能够使大学生形成对社会主义 核心价值观的向往和追求, 并逐步成为支配其人生行为 的精神动力的教育活动。真正成长为一名坚定的马克思 主义者可能是一个漫长的、不断进步的过程, 有可能需 要一个人一生的奋斗, 对大学生实施信仰教育的目的在 于使学生始终朝着这个方向不断迈进, 不断提高自己的 思想觉悟, 不断坚定自己的理想信念, 始终走在时代前 列。

信仰班（高级）又称青年马克思主义者培训班（简 称“青马班”) 是学生干部培训的最高层次, 是培养青年 马克思主义者的重要平台, 是广大学生信仰教育的辐射 窗口, 是未来杰出校友培养的基地。青马班是针对经过
初级或中级的系统培训后或按照“学习好、能力强、表现 优”的条件在全校范围内严格选拔的学生干部精英代表, 开展的以社会主义核心价值观为核心的诸如: 人生信仰、 远大理想、公民意识、责任担当、家国情怀等理论实践 强化教育, 旨在培养“信仰坚定、理想远大、视野开阔、 德才兼备、堪当重任”的未来各行各业骨干人才。培训形 式为“小班授课和大班活动并重”、“小班活动和全校活动 并重”、“理论教学和实践训练并重”、“校内培养和校外 培养并重”。

3.3.3 着眼社会和谐, 以夯实女大学生发展后劲为核心, 设置“女子学院”。

近十年来, 我国高等教育除了大学生入学规模在增 长以外, 入学的男女生比例也在悄然发生变化, 综合高 校女生数量占到了一半左右, 文科、师范类高校中在校 女生数量甚至高于男生。女大学生未来不仅要撑起实现 “中国梦”的“半天边”, 还要在社会和家庭中“相夫教子”、 承载着促进家庭和社会和谐的重担, 因此, 对优秀女大 学生进行精英化培训, 是以人为本、尊重女性、因材施 教、加强性别意识教育的生动体现, 是以提高女性素质 为逻辑起点进而提高全民族素质的重要战略举措。

“女子学院” 是在校党委的领导下由学生工作部门具 体负责的对全校女大学生培训工作予以指导和管理的常 设机构, 采取校院两级管理模式。学校学生工作部门负 责全校女生培训工作整体规划, 并具体负责校级“女子学 院”培训工作的组织实施。学院学工组织具体负责院系女 大学生的培训工作。

“女子学院”通过“高雅女生、自强女生、内涵女生和 幸福女生”四大课程体系的系统教学, 提高女大学生的道 德自信、学术自信、能力自信和气质自信, 提高女大学 生的社会生存、适应和发展能力, 促进女大学生的健康 成长、为就业创业工作和未来的家庭和谐、社会和谐打 下基础。采取案例教学、角色模拟和互动教学为主, 面 授学习、场景训练、专家答疑等多种形式为辅的科学的 教学方法, 全方位的为女大学生带来更多生活和生命体 验。形成颇具特色的 “崇德、至爱、博学、尚美”的女大 学生培养文化。

\section{参考文献(References)}

[1] The Outline of National Long-term Plan For education Reform and Development Program (2010- 2020).

[2] The Central Committee of the Communist Party of China, the State Council on Further Strengthening and Improving Ideological and Political Education for College Students. (The 16th Files). 